\title{
Academic Misconduct: An Investigation into Male Students' Perceptions, Experiences \& Attitudes towards Cheating and Plagiarism in a Middle Eastern University Context
}

\author{
Bilal M. Tayan ${ }^{1}$ \\ ${ }^{1}$ Graduate School of Education, Exeter University, United Kingdom \\ Correspondence: Bilal M. Tayan, Graduate School of Education, Exeter University, United Kingdom. E-mail: \\ bt275@exeter.ac.uk
}

Received: October 29, 2016

Accepted: November 10, $2016 \quad$ Online Published: November 17, 2016

doi:10.5539/jel.v6n1p158

URL: http://dx.doi.org/10.5539/jel.v6n1p158

\begin{abstract}
Academic misconduct in many educational institutions in the Middle East is an inherent problem. This has been particularly true amongst the university student population. The proliferation of the Internet and the ownership of mobile and electronic devices, have, in part, witnessed rates of cheating, plagiarism and academic misconduct cases steadily increase across higher education contexts. Though the growth of the Internet as an information source and gateway to knowledge has increased substantially in recent years, it has, however, opened up a plethora of varying forms and rates of academic dishonesty. This study was conducted through an online Likert scale questionnaire. Its purpose was to investigate first year male undergraduate students' attitudes, experiences and perceptions towards plagiarism and cheating in a university located in Saudi Arabia. The study aimed at addressing themes in relation to the meaning, forms, source, frequency and reasons of cheating and plagiarism. The study indicates that cheating and plagiarism is common among students, while a need to address student awareness and clarify student expectations towards academic integrity was also identified. The study also proposes several recommendations to alleviate the levels of academic misconduct, be it cheating in exams or plagiarising content, in the Saudi university context.
\end{abstract}

Keywords: academic misconduct, educational integrity, plagiarism, student attitudes

\section{Introduction}

The development and subsequent surge in telecommunication platforms has been driven by the increased adoption of wireless personal devices, the changes in lifestyles, work habits and social norms. Increased use of electronic devices and readily available access to online context among the student population has created an opportunity for cheating and plagiarism to grow in university contexts across the world (Graham et al., 1994; Genereux \& McLeod, 1995). The lack of educational integrity across many contexts has now become a widespread phenomenon and is being facilitated by the advent of the Internet and the explosion in the growth of smartphones and other hand held electronic devices. As such, this has enabled the access, transmission and dissemination of content in more simple, frequent, yet dishonest means. The popularity of technology has taken plagiarism and cheating to a new level which has consequently made incidences involving cheating in exams or plagiarising from both conventional printed literature and electronic online sources more recurrent. This form of unethical behaviour can be referred to as academic dishonesty.

\subsection{Academic Misconduct Defined}

According to the University of Edinburgh (2016), academic dishonesty can be defined as "any type of cheating that occurs in relation to a formal exercise". This may include acts of paraphrasing, lack of or no citation of submitted academic work, deceit in or falsification of data collection, cheating in exams and deceit by colluding and financially rewarding a third party to compile a written piece of work. From the review of literature, academic dishonesty can be deduced as being the deliberate attempt to fabricate, falsify or engage in unauthorised behaviour that is relevant to a student's participation and progression in academic work. Academic dishonesty can therefore be divided into three categories, i) plagiarism; ii) cheating; and iii) other academic misconduct behaviour. Plagiarism refers to the act of imitating the ideas, thoughts and language of a person's work without authorisation or acknowledging the original author. The second category, cheating, can be 
described as the action of deception or eluder thereby influencing an outcome by fraudulent means. Thirdly, a final category of educational misconduct can be referred to as other forms of academic misconduct. This final broad category can include, but is not limited to, the falsification, fabrication, misrepresentation, distortion and invention of, for example, data relevant to research, student records, attendance records and examination marks (Moon, 2006).

\section{Educational Integrity: A Fallacy of Composition}

The vast types and forms of academic misconduct can therefore make it challenging to detect and counteract (Ashworth, Bannister, \& Thorne, 1997). However, Bandura (1991) suggests that a large and growing number of students do not see plagiarism as dishonest, deceitful, immoral or even criminal. This is supported by Kraus (2002, p. 84), who points out a large and increasing number of students "simply do not see plagiarism as wrong". Kraus (2002) further goes on to argue that though students are aware they should not engage in the act of plagiarism, it has come to the point where students repeatedly identified or caught engaging in plagiarism-related behaviour may only consequently witness a minor misdemeanor offence being issued. This can be particularly true among university management across many Gulf learning institutions where rates of cheating and plagiarism have become a great concern (Ahmadi, 2012). This fallacy of composition gives growth to a vicious cycle of academic immorality and the result of which may simply include the re-submission or editing of submitted work. This fallacy, this notion of working to prevent academic dishonesty or this misleading form of "student punishment" has thus witnessed a substantially augmented frequency in cases of academic dishonesty, particularly in academic transcript submissions, with the coining of the new "cut and paste" culture prevalent among many Middle East and North African (MENA) countries (Hosny \& Fatima, 2014). Nonetheless, with more and more students owning electronic handheld devices, the possibilities, opportunities, persistence and recurrence of plagiarism and cheating has been magnified to unprecedented levels. Attributing the influence of electronic handheld devices as a catalyst to increasing global levels of academic misconduct, it may undeniable that technology has made it easier to access, disseminate and submit work falsely and to cheat in examinations through the use of smart spy technology including micro ear pieces or spy cameras linked to smart-watches. These devices create the convenience of copying and transmitting data both inside and out of the classroom. Though students may not immediately reflect on the consequences of their actions, as grade improvement is perhaps the only target they are concerned with.

Yet, if students acknowledge that plagiarism and cheating is wrong, one must ask, why do students cheat? One possibility could be due to the abundance, relative low cost and mobility of electronic devices that have made it tempting and possible to cheat in exams or to easily access information and disregard attributing work to the relevant author. Here, McCabe's (2001) research highlights the significance of the Internet on cheating and plagiarism cases amongst high school students in the US. Interestingly, he points out that while the Internet is used as a common medium for communication, particularly with the use of social media websites, students do not properly recognise the Internet as a legitimate academic tool or a formal source of information, in contrast to conventional print media, including academic books and journals. Translating this, students commonly see the Internet, and the opportunities it poses as merely "public knowledge and does not need to be footnoted-even if it is quoted verbatim" (McCabe, 2001, p. 41). According to Graham et al. (1994), and supported by McCabe's (2001) research, several compelling factors which facilitate cheating and plagiarism include pressure from parents and teachers to perform academically, as well as the increasing difficulty of student learning materials and programmes of study, were recognised as significant variables for students to engage in academic misconduct. A significant concern in the research also highlighted student perceptions towards their teacher's attitude regarding cheating.

According to McCabe's (2001) study, students believed their teacher showed little or no interest if they had cheated in assignments or exams. McCabe (2001) attributed this to the bureaucracy of school administration and the complexities involved in monitoring and pursuing individual cases of assumed cheating and plagiarism within the school. Perhaps, the lack or limited availability of modern and sophisticated plagiarism analysis software should also be attributed as a correlating factor to the level of cheating and plagiarism at schools. Nevertheless, McCabe, Trevino and Butterfield (2001) and Nadelson (2007) attribute additional factors influencing unethical academic behaviour. They cited factors including gender, participation in extra-curricular activities, and age as significant factors. Pulvers and Dierkhoff (1999) also attributed environmental and cognitive development factors in influencing learners to engage in various forms of academic misconduct. In a study conducted by Simon et al. (2003), the researchers found a strong correlation between the situated environment learners were in and the levels of academic misconduct cases. Yet, analysing, exploring and correlating them may be extremely challenging due to their very nature. 
Understanding the nature of cheating and plagiarism is complex (Ashworth, Bannister, \& Thorne, 1997). Tackling this multifaceted phenomenon may be testing; as such, the academic community constantly faces challenges in preventing cases of unethical behaviour rather than finding a cure to one. This is possibly the result of the inherent nature in identifying the tangible and intangible variables involved, the level of support from educational management and stakeholders in addressing the problems and implementing systems to counter-act such behaviour. However, in the battle against plagiarism and cheating, what can be witnessed is a growing number of educational institutions publishing and widely disseminating codes of conduct or codes of ethics for their academic staff and student population. The writing and free distribution of this literature, usually found in a university student handbook, has now become a common practice in all academic disciplines across the globe and is widely recognised as not only an essential part of a course syllabus, but also a significant factor in deterring cheating and plagiarism in school or university contexts. McCabe, Butterfield and Trevino (2003, p. 367) suggest that the distribution of a university code of ethics have witnessed positive attitudes by faculty towards their institution and are "more willing to allow the system to take care of monitoring and disciplinary actions" than those institutions with no codes of conduct currently in place. The positive effect a code of conduct/ethics on faculty members may thus subsequently create positive influences on student academic behaviour (Noddings, 2002).

Nonetheless, despite efforts by faculty staff and the college administration in attempting to identify culprits and stamp-out academic misconduct in favour of educational integrity, the researcher still believes the frequency of cheating in exams and the levels of plagiarism in assignment submissions within the researcher's teaching context is still a serious concern for academics and universities in the MENA region. Within the context of the study, the researcher felt compelled to engage in addressing and exploring the phenomenon of cheating and plagiarism. This ethical dilemma has become so severe in some cases, that it has become well known among some student groups, particularly with first year students new to the university learning environment, that some teachers turn a blind eye to such behaviour.

Subsequently, addressing this phenomena and exploring the extent to which its prevalenceis evident is an interesting area for further study, particularly where there has been little research conducted in the Middle Eastern or Gulf region. Understanding the factors to such behaviour, attitudes and learner perspectives may provide a platform to which academics and policy makers can address and target academic dishonesty more effectively. Consequently, studying perceptions, experiences and attitudes towards cheating and plagiarism may also assist students in realising the risks, dangers and consequences of engaging in unethical behaviour at the academic level, while also helping teachers, policy makers and educational institutions overcome, or at least limit the growing trend in academic dishonesty. In addressing this concern, it is envisaged that the study will highlight what male students understand by the terms "cheating and plagiarism", and to explore opinions as to why learners participate in academic misconduct. It is hoped that this would later assist academics, university management and policy makers to encapsulate the various factors involved in comprehending why students cheat and plagiarise and how best to target and tackle the issue from the core. In doing so, it may perhaps later provide a support structure to academics, management and other higher education institutions and other places of learning in identifying and overcoming the overwhelming growth in academic misconduct cases across the MENA region and to better prepare students in critical thinking, reflection, academic writing, citation and exam preparation skills. This would therefore result in better student awareness in realising the importance of correct referencing conventions and highlight the dangers and consequences of plagiarism and cheating in academia.

\section{Study Context}

The context of study was based on 138 first year male undergraduate students studying in a business administration degree programme at a Saudi state university. This context was chosen as it is the location the researcher is employed at, which consequently enabled easy access to the participants for the study to be conducted. The study focused on responses from male only students due to the gender segregation policy of the university. An online questionnaire in English with an Arabic translation was created to enable students to participate in the study in private and at their own convenience, without teacher or peer pressure that may have otherwise influenced the outcomes of the results. Being first year undergraduate students, the questionnaire was the first time the new undergraduate learners experienced research into their personal attitudes and experiences on a sensitive topic. To the best of the researcher's knowledge, this was also the first time a study on cheating and plagiarism was conducted in the university. Consequently, it was believed the study outcome and the recommendations put forward would assist the college and the university as a whole, to discuss and establish new standards and develop pre-existing practices to combat academic dishonesty among students. 


\subsection{Research Purpose}

While numerous publications address the problems concerned with cheating and plagiarism, from the literature available, it was felt there was a lack of study into whether cheating and plagiarism related behaviour was prevalent in a Saudi university context and what university student attitudes, perceptions and experiences towards cheating and plagiarism were. It was felt, that conducting research in a Saudi university context would help identify and address any possible shortcomings in academic dishonesty prevalent among the university population. Furthermore, it was also felt that studying and researching student attitudes, perceptions and experiences towards such behaviour would create a conscious awareness for students, faculty staff and management about the dangers and consequences of unethical conduct. To this end, the purpose of this research was to identify student attitudes, perceptions and experiences regarding cheating and plagiarism and compare the findings with previous research in the area.

\subsection{Methodology}

The research conducted was solely on first year male undergraduate students at a business college in a Saudi university. An online questionnaire was used to investigate, explore and analyse male students' perceptions, experiences and attitudes towards cheating and plagiarism in their learning context. Participation in the study was open to all first year male students at the business college, regardless of age or views towards the research. Students were encouraged to participate in the study by the researcher. The students were informed that engaging in the study would better assist them in understanding themselves as students in a professional learning context, their learning environment and what was expected of them as university undergraduate students working towards a degree in Business Administration. As the survey was uploaded on an open online platform (http://bit.ly/1zkNOtm), no authentication credentials or password log-in was required in order to access and complete the questionnaire. The final page of the questionnaire thanked all respondents for participating in the survey. With regards to the ethical guidelines of data collection and publishing, the student questionnaires received protected the participant's privacy and anonymity by eliminating factors which may have revealed their identity. Details such as name, address, contact details and so forth were not asked nor revealed and the submitted online questionnaire which were linked to an Internet Protocol address, that allow the location of an Internet connected digital device to be pinpointed, were not accessed. Anonymity and confidentiality of the information obtained from the questionnaires was treated ethically and all results were stored securely in the researcher's personal office. Here, it is also important to note that Dornyei (2007) advocates a clear level of transparency between a researcher and participant. For this purpose, participants were given the opportunity to submit the online questionnaire within seven days of being informed. It was felt this period was enough to enable participants to comfortably review and respond to the questionnaire at a time and in an environment that suited them.

The survey was based on a Likert scale, with closed-ended questions that were divided into four categories. These categories included fifteen questions which fell under the categories of i) the meaning of cheating and plagiarism; ii) the forms of cheating and plagiarism; iii) the sources and frequency of cheating and plagiarism, and finally; iv) the reasons for cheating and plagiarising. In the first category, seven questions were posed to students which intended to analyse whether students understood the concept of plagiarism, their attitudes towards cheating plagiarising unaccredited work and whether they were aware of the prevention systems in place to combat plagiarism/cheating. The first category aimed at exploring the level of awareness about the consequences of academic dishonesty among learners. The second category of questions analysed what students perceived as an act of cheating or plagiarism, while the third category of questions focused on identifying whether academic misconduct was a regular occurrence at the university, whether students had engaged in cheating and plagiarism as well identifying the frequency of cheating or plagiarism incidences students felt were apparent in exams or class assignments. The fourth and final category aimed at studying the reasons students felt they were compelled to engage in acts of plagiarism and/or cheating.

\section{Results}

Table 1 depicts the first category of questions that aimed at exploring the level of awareness about the consequences of academic dishonesty among learners. 
Table 1. Student awareness and consequences of academic dishonesty

\begin{tabular}{cccccc}
\hline & $\begin{array}{c}\text { Meaning of } \\
\text { plagiarism }\end{array}$ & $\begin{array}{c}\text { If written work by a } \\
3^{\text {rd }} \text { party is plagiarism }\end{array}$ & $\begin{array}{c}\text { Awareness university } \\
\text { using plagiarism software }\end{array}$ & $\begin{array}{c}\text { Plagiarism software discourages } \\
\text { academic dishonesty }\end{array}$ & $\begin{array}{c}\text { Informed of academic } \\
\text { consequences }\end{array}$ \\
\hline Yes (\%) & 64.5 & 62.3 & 20.3 & 31.9 & 39.9 \\
No (\%) & 18.1 & 21.0 & 79.7 & 33.3 & 60.1 \\
Not Sure (\%) & 17.4 & 16.7 & n/a & 34.8 & $\mathrm{n} / \mathrm{a}$ \\
\hline
\end{tabular}

An examination of the study results highlight $35 \%$ of respondents were not aware or not sure what plagiarism meant. Of the respondents that were aware of what plagiarism entailed, $42 \%$ of respondents had considered paying a third party to write their assignment. This figure is in similar comparison to the response in which a total of $37 \%$ of respondents replied No or were Not Sure whether submitting work written by a third party was a form of plagiarism. Yet nearly $80 \%$ of participants were not aware plagiarism software is used by the university to detect academic dishonesty. Asked whether the use of plagiarism software used in the university would discourage or prevent them from plagiarising, a significant amount of respondents, 33\%, replied No, while $34 \%$ were Not Sure. In similar respects, asked if the university had ever informed or advised them of the consequences of academic dishonesty, a relatively high ratio of students, $60 \%$, answered No. This negative correlation towards plagiarism and cheating prevention also highlighted that $24 \%$ of students questioned would expect a light warning or even no punishment if caught in academic dishonesty.

Table 2. Forms of cheating and plagiarism

\begin{tabular}{ccccccc}
\hline & $\begin{array}{c}\text { Submitting work } \\
\text { by a friend }\end{array}$ & $\begin{array}{c}\text { Paying someone } \\
\text { to do the work }\end{array}$ & $\begin{array}{c}\text { Copying } \\
\text { another student }\end{array}$ & $\begin{array}{c}\text { Using illegal } \\
\text { devices in an exam }\end{array}$ & $\begin{array}{c}\text { No citation/reference } \\
\text { in work }\end{array}$ & $\begin{array}{c}\text { Para-phr } \\
\text { asing }\end{array}$ \\
\hline Yes (\%) & 44.2 & 38.0 & 45.0 & 64.3 & 41.9 & 30.2 \\
\hline
\end{tabular}

The lack of recognition in what exactly cheating or plagiarism entailed was also reflected in Table 2, under the second category of Forms of Cheating and Plagiarism. Here, $64 \%$ of participants agreed that using unauthorised aids in an exam is a form of cheating, yet, ironically, only $38 \%$ of respondents considered paying someone to write an assignment as a form of plagiarism. Similarly, $42 \%$ of students would not consider poor referencing and citation as a form of plagiarism. The lack of awareness into what defines plagiarism and the relatively high ratio of students showing attitudes of engaging in academic misconduct is also reflected by the data which illustrates only $30 \%$ of respondents highlighted that paraphrasing was a form of plagiarism. As such, the support for academic honesty and integrity in the study context is seen as negative, primarily because many respondents were not aware of what plagiarism was and how various forms of behaviour students engaged in during the submissions of academic assignments fell under plagiarism. This is reinforced by the overall attitudes and frequency students had towards cheating in exams.

Table 3. Frequency of cheating and plagiarism

\begin{tabular}{cccc}
\hline & In an exam or course work & Paying a 3rd party & Through peer collaboration and deception \\
\hline Always (\%) & 18.7 & 23.6 & 42.0 \\
Sometimes (\%) & 56.9 & 30.6 & 29.0 \\
Rarely (\%) & 17.9 & 25.5 & 14.6 \\
Never (\%) & 6.5 & 20.3 & 14.4 \\
\hline
\end{tabular}

Table 3 highlights the frequency of cheating and plagiarism. Under this third category, asked whether in their course of study, how often they were aware of cheating in an exam, assignment or homework activity, $57 \%$ of 
students responded saying that cheating occurred sometimes, while approximately $20 \%$ said there was always cheating in assessed academic activities. This is perhaps in part due to the $42 \%$ of participants who illustrated that cheating and plagiarism is common among their peers.

Table 4. Assessing the reasons for cheating

\begin{tabular}{cccccc}
\hline & $\begin{array}{c}\text { Lack of time to } \\
\text { complete assessment }\end{array}$ & $\begin{array}{c}\text { Lack of interest to } \\
\text { complete assignment }\end{array}$ & $\begin{array}{c}\text { Lack of skills to effectively } \\
\text { complete assignment }\end{array}$ & $\begin{array}{c}\text { Difficulty of } \\
\text { exam/assignment }\end{array}$ & $\begin{array}{c}\text { The need to score } \\
\text { a high grade }\end{array}$ \\
\hline Agree (\%) & 38.8 & 37.1 & 45.7 & 58.6 & 81.9 \\
Disagree (\%) & 61.2 & 62.9 & 54.3 & 41.4 & 10.1 \\
\hline
\end{tabular}

In the final category, where Table 4 explores the reasons for cheating, $82 \%$ of student respondents highlighted cheating was predominantly due to the need to score a high grade, while $59 \%$ of responses suggested the level of difficulty in exams compelled them to cheat. An interesting result highlighted that $46 \%$ of students lack skills to effectively complete their assignments.

\section{Discussion}

The study highlighted several key issues that are worthy to note. The results illustrated that a significant $35 \%$ of students noted they lacked little or no knowledge into what exactly constituted plagiarism. Furthermore, while only $62 \%$ of students believe submitted work written by someone else is a form of plagiarism, suggests the remaining $38 \%$ of students are therefore unclear in what plagiarism entails and thus, this ill-defined perception in understanding a clear definition of what plagiarism entails becomes evident. These results do suggest that plagiarism and cheating can be interpreted differently by many students. While this is clear, it is also important to note from the study that the results can be interpreted in many ways by different people. One must understand that even slight changes in variables, such as the type of institution, the geographic location, the type of education delivery, i.e., face-to-face instruction or online distance learning, the size of the university, gender and so forth, can all have significant influences on the results and their interpretations.

What the study has highlighted is that while students do acknowledge academic dishonesty is wrong, $57 \%$ of students nevertheless recognise that cheating sometimes occurs in exams, homework and course assignments. If this is the case, then one must wonder why there is a remarkable difference in what students believe is wrong and the type/frequency of academic dishonesty they engage in. While some variables are extremely difficult to measure, including the influence of body language, eye contact and other non-verbal cues, there however seems to be a correlation between knowing what is wrong and behaving in unethical academic behaviour.

From the results, indications highlight that, perhaps due to a lack of relevant awareness or ignorance in what is right, what is acceptable or what students can perhaps get away with, $42 \%$ of students have considered paying someone to write their assignments. On the other hand, $58 \%$ of students said they had never considered or asked someone to complete their assignments for a financial incentive. The relatively high percentage of students who have considered paying someone is surprising, especially when it can be obvious when a paper is not written by an underperforming student or a student whose language or written capabilities are not to the standard of the submitted text. Perhaps the lack of effective training from primary and high schools are partly responsible for the lack of effective skills in creative writing and expression among many of the student population in Middle Eastern universities. This therefore creates a cycle of frustration and fuels temptation to seek private tutors or organisations that are willing to write or complete essays and projects for, at times, considerable amounts of money. For students, the risks perhaps far outweigh the resulting punishment, where, according to the study results, $22 \%$ of students believe the punishment for cheating would only result in a light misconduct punishment such as a verbal warning, while $54 \%$ of students believed they would only receive a written warning.

With regards to the use of electronic plagiarism software in the university study context, the male student respondents highlighted overwhelmingly that nearly $80 \%$ were not aware the university subscribe and have access to a plagiarism checking software application. Though $20 \%$ of respondents acknowledged their awareness of a plagiarism checking software in use at the university, the vast majority of students were not aware. The lack of understanding, knowledge and awareness of the practices that are in place to combat or to prevent cheating and plagiarism perhaps could be a contributing factor to the frequent cases of plagiarism in the university study context. Yet, asked if they were aware a plagiarism checking software being used would discourage them from 
plagiarising and being involved in academic dishonesty, only $32.9 \%$ of respondents responded positively. On the other hand, $33.3 \%$ of students said being aware of the use of plagiarism checking technology would not discourage them from plagiarising, while $34.8 \%$ of students were unsure if it would discourage them from behaving in an academically dishonest manner. In similar respects, $60 \%$ of students highlighted that the university had never informed them of the consequences of academic dishonesty. Consequently, one can therefore deduce that the relatively high percentage of students who would not be discouraged from plagiarising in the face of anti-plagiarism technology and the disregard for academic integrity among many student respondents, is a concerning matter. It is therefore interesting to ponder on the possible factors at play behind students' negative attitudes and perceptions towards educational integrity.

Nevertheless, it is surprising more than half of the respondents illustrated that a written formal warning would be issued if caught plagiarising, while $18 \%$ believed they would be expelled from the university. Consequently, if students acknowledge that punishment would follow through after acts of educational misconduct then why do they engage in such behaviour? Here, students replied several factors in their drive to cheat or plagiarise, with approximately $60 \%$ of student respondents noting the level of difficulty in exams, while some of the same respondents highlighted the need to score a high mark as a key driver to cheat or plagiarise during their programme of study. This is supported by the fact that from the survey results, responses showed a tendency for students to cheat with approximately $57 \%$ noting cheating in exams, assignments and homework activities occurred sometimes throughout the course of their study. Though, despite management and teaching staff punnishing students who engage in plagiarism and cheating, some students perhaps realise that academic misconduct is the only way for them to pass a course, progress to the next year of study or that the decision to engage in plagiarism and cheating is a concious one based on the percieved misconception that the benefits far outweigh the risks attributed to being caught (Williams \& Hosek, 2003).

In any case, the nature of cheating and plagiarising, attempting to categorise attitudes, identify perceptions and measure increases, decreases or significant fluctuations of cheating and plagiarism is difficult due to its very nature. Assessing student perspectives and attitudes is challenging particularly due to the changing attitudes learners may have towards academic dishonesty over time. Even measuring cheating and plagiarism cases depend on the whether the student gets caught. Hence, it would be appropriate to refer to Ashworth, Bannister and Thorne (1997) who argue that effectively comprehending the intricacies involved in identifying cheating and plagiarism is, by its very nature, convoluted.

Many of the typical incidences of plagiarism or cheating involve a peer, friend or third party writing an essay or completing a project (Graham et al., 1994). The study showed and supported this form of cheating to be the highest among other controversial types of cheating, with $43.1 \%$ of respondents confirming this. Having a friend or peer complete course assignments far outweighed other sources or forms of cheating and plagiarism including copying and pasting from the Internet (35.8\%), asking a person of knowledge/a teacher $(12.2 \%)$ or a former student $(8.9 \%)$. While copying and pasting from the Internet was highlighted as one of the easiest way to plagiarise and cheat, it is an argument of controversy, particularly when information on the Internet may not always be static and may include information which is difficult to reference due to a lack of referencing details.

\subsection{Pedagogical Implication and Future Direction}

The use of mobile technology as an information communication platform has increased substantially in recent years and has shown no signs of maturity or decline. As there has been an upsurge in mobile communications, opportunities for educational practitioners to utilise the digital revolution is quick evolving into a debate into the feasibility of using technology and mobile devices to support students with their learning processes. Though the growth of e-cheating cases has steadily grown in response to the developments of information communication technologies, students of this new digital native age may indeed become cheat savvy individuals. Students of the Web 2.0 smart-mobile digital age have thus had opportunities to be more cunning thrust upon them in their ability to manipulate the use of technology to immoral ends. Students today, particularly in the Middle Eastern context, reply on open source information from the internet or printed media to complete academic work. Though this may be stunning to some, it is the lack of student awareness and sufficient knowledge into what cheating is and what constitutes plagiarism in written academic submissions that dilutes such interpretations among some students, particularly those new to university life. It is thus essential that educational institutions of all types not only create student awareness of what cheating and plagiarism is, but they must also simultaneously clarify and openly advertise when certain types of undesirable student behaviour becomes a serious offence that results in serious consequences. 
Nonetheless, for the impact of academic dishonesty to be measured and reduced in study contexts, it must not only be addressed, but future empirical evidence must also take into account the significance of technology and how technology itself can be used to counter-act or prevent students cheating in exams or plagiarising in written assignment papers. Being aware of the surge in online distance learning is also significant and can create disturbing realisations of plagiarism and cheating in that specific learning environment compared to traditional face-to-face instruction. Perhaps exploring the nature of academic dishonesty among gender groups within these two learning environments would construct further interesting insights and create new developments in comprehending the extent and nature of cheating and/or plagiarism and how learning environment types reflect the tendency and prevalence of cheating and plagiarism. While it would also be interesting to study whether there are significant differences in academic dishonesty reported between first year through to final year undergraduate students, as well as comparisons with postgraduate level students, this area of research is still at a premature stage and further study is required to understand and address the full extent of plagiarism and cheating in Middle Eastern university contexts.

Addressing these concerns and devising proactive awareness strategies and regular workshops demonstrating effective citation and referencing methods to tackle the endemic culture of cheating and plagiarism in some Middle Eastern university contexts is a fundamental step to positive change. Policy not only needs to be introduced for the sake of doing something, but effective action to prevent, rather than cure, is an essential platform for policy makers, university management and teaching staff if the unprecedented levels of cheating and plagiarism is to be tackled. Comparative data in analysing the extent of academic dishonesty is important, but learning from other countries with superior education systems, such as the Finnish model, and adapting it to the learner environment is important if progress is to be made.

\section{Conclusions}

Prompted by concerns in the frequency of cheating and plagiarism among university students in the context of the researcher's teaching environment, this paper sampled first year undergraduate business administration male students through an online questionnaire. A series of questions were administered that focused on learner attitudes, experiences and perceptions towards cheating and plagiarism indicated that though nearly three quarters of respondents acknowledged what plagiarism and cheating practices entailed, results highlighted that students would still sometimes engage in cheating or plagiarism during examinations or with assessed coursework. This was perhaps due to the lack of information and awareness students had into what constituted acts or practices of plagiarism. While the study found that cheating and plagiarism was a common offence among some students who displayed indifferent attitudes towards the immorality of these practices, the results suggest that faculty and university management should be directing resources and address the rationale behind academic dishonesty. This is particularly true when predominant majority of the student respondents highlighted the university had never informed or advised them of the consequences of academic dishonesty.

In the context of this study, plagiarism and cheating seems to be common among learners. It appears that many students participate in cheating related activities due to the lack of the severity in any concurrent punishment that may follow. In the case of plagiarism, while many students did not show a clear understanding of plagiarism, university management and teaching staff have a responsibility to educate their students in understanding and adopting and practicing conventional referencing and citation skills. Addressing student rationalisations behind the various acts of academic dishonesty is fundamental. Consequently, the academic community has a duty and is obliged to address this by educating their learners about writing techniques, APA or Harvard referencing convention styles or even allowing learners to access plagiarism checking software. These are all important steps in preventing academic dishonesty in language and written expression if learners are to be truly successful graduates.

\section{References}

Ahmadi, A. (2012). Cheating on exams in the Iranian EFL context. Journal of Academic Ethics, 10, 151-170. http://dx.doi.org/10.1007/s10805-012-9156-5

Ashworth, P., Bannister, P., \& Thorne, P. (1997). Guilty in whose eyes? University students' perceptions of cheating and plagiarism in academic work and assessment. Studies in Higher Education, 22, 187-203. http://dx.doi.org/10.1080/03075079712331381034

Bandura, A. (1991). Social cognitive theory of moral thought and action. In W. M. Kurtines, \& J. L. Gewirtz (Eds.), Handbook of Moral Behavior and Development (Vol. 1, pp. 45-103). Hillsdale, NJ: Erlbaum. 
Dornyei, Z. (2007). Research Methods in Applied Linguistics. Quantitative, Qualitative and Mixed Methodologies. Oxford: Oxford University Press.

Genereux, R. L., \& McLeod, B. A. (1995). Circumstances surrounding cheating: A questionnaire study of college students. Research in Higher Education, 36(6), 687-704. http://dx.doi.org/10.1007/BF02208251

Graham, M. A., Monday, J., O'Brien, K., \& Steffen, S. (1994). Cheating at small colleges: An examination of student and faculty attitudes and behaviors. Journal of College Student Development, 35, 255-260.

Hosny, M., \& Fatima, S. (2014). Attitude of Students Towards Cheating and Plagiarism: University Case Study. Journal of Applied Sciences, 14, 748-757. http://dx.doi.org/10.3923/jas.2014.748.757

Kraus, J. (2002). Rethinking plagiarism: What our students are telling us when they cheat. Issues in Writing, 13(1), 80-95.

McCabe, D. (2001). Cheating: Why students do it and how we can help them stop. American Education, 38-43.

McCabe, D. L., Trevino, L. K., \& Butterfield, K. D. (2001). Dishonesty in academic environments. Journal of Higher Education, 72(1), 29-45. http://dx.doi.org/10.2307/2649132

McCabe, D. L., Trevino, L. K., \& Butterfield, K. D. (2003). Faculty and academic integrity: The influence of current honor codes and past honor code experiences. Research in Higher Education, 44, 367-385. http://dx.doi.org/10.1023/A:1023033916853

Moon, J. (2006). Academic honesty, plagiarism and cheating: A self-instruction unit for postgraduate students. $\begin{array}{llll}\text { Retrieved July } & 7, & \text { from }\end{array}$ http://www-old.hud.ac.uk/schools/hhs/teaching_learning/plagiarism_handout3.pdf

Nadelson, S. (2006). The environment and student moral behavior. Journal of College and Values, 7(5), 1-9.

Noddings, N. (2002). Educating Moral People: A caring Alternative to Character Education. New York: Teachers College Press.

Pulvers, K., \& Diekhoff, G. M. (1999). The relationship between academic dishonesty and college classroom environment. Research in Higher Education, 40(4), 487-499. http://dx.doi.org/10.1023/A:1018792210076

Simon, A. S., Carr, J., McCullough, S., Morgan, S., Oleson, T., \& Resse, M. (2003). The other side of academic dishonesty: The relationship between faculty skepticism, gender and strategies for managing student academic dishonesty cases. Assessment \& Evaluation in Higher Education, 28(2), 193-207. http://dx.doi.org/10.1080/02602930301669

University of Edinburgh. (2016). What is academic misconduct (online). Retrieved July 8, 2016, from http://www.ed.ac.uk/academic-services/students/conduct/academic-misconduct/what-is-academic-miscondu ct

Williams, M. S., \& Hosek, W. R. (2003). Strategies for Reducing Academic Dishonesty. Journal of Legal Studies Education, 21, 87-95. http://dx.doi.org/10.1111/j.1744-1722.2003.tb00326.x

\section{Copyrights}

Copyright for this article is retained by the author(s), with first publication rights granted to the journal.

This is an open-access article distributed under the terms and conditions of the Creative Commons Attribution license (http://creativecommons.org/licenses/by/4.0/). 